\title{
Alveolar MMP28 is associated with clinical outcomes and measures of lung injury in acute respiratory distress syndrome
}

\author{
Eric D. Morrell, Carmen Mikacenic, Ke-Qin Gong, Susanna Kosamo, Mark M. Wurfel and Anne M. Manicone*
}

Keywords: Acute respiratory distress syndrome, Alveolar macrophages, Matrix metalloproteinases

\section{Dear Editor,}

Alveolar macrophages (AM) express a unique repertoire of matrix metalloproteinases (MMPs) that have downstream effects on inflammatory mediators involved in acute respiratory distress syndrome (ARDS) pathogenesis. MMP28 is the newest member of the MMP family and has been shown to be upregulated in inflammatory conditions such as idiopathic pulmonary fibrosis [1]. In animal models of lung infection, MMP28 plays a key role in macrophage chemotaxis [2] and in modulating macrophage polarity [3]. AM polarization plays a central role in orchestrating alveolar inflammation and repair in ARDS, and we have previously shown that AM transcriptional programs are associated with ARDS clinical outcomes such as ventilator-free days (VFDs) [4]. Therefore, our primary hypothesis was that AM MMP28 gene expression is associated with VFDs in subjects with ARDS. Secondarily, we hypothesized that AM MMP28 gene expression and alveolar MMP28 concentrations are associated with $\mathrm{P}_{\mathrm{a}} \mathrm{O}_{2} / \mathrm{F}_{\mathrm{i}} \mathrm{O}_{2}$ ratio ( $\mathrm{P} / \mathrm{F}$ ratio), percentage alveolar neutrophils (\% PMNs), and total protein levels.

We analyzed bronchoalveolar lavage fluid (BALF) from subjects previously enrolled in a phase-II trial [5] of omega-3 fatty acids for the treatment of ARDS $(n=76)$ (Table 1). In a subset of these patients $(n=25)$, AMs were purified from BALF by negative selection as previously described [4]. Samples were obtained from subjects within $48 \mathrm{~h}$ of ARDS onset and prior to them receiving

\footnotetext{
* Correspondence: manicone@uw.edu

Division of Pulmonary, Critical Care, and Sleep Medicine, Center for Lung Biology, University of Washington, 850 Republican St, Seattle, WA 98109, USA
}

study drug. We extracted RNA from isolated AMs, assessed it for purity, and then reverse-transcribed it into CDNA. RT-PCR was performed per the manufacturer's instructions using HPRT and MMP28 (Hs01020031_m1) primer probe sets from Applied Biosystems. BALF MMP28 was measured using an ELISA (Cat \#: LSF12061) specific for human MMP28 per the manufacturer's instructions (LifeSpan Biosciences). Specimens with an MMP28 concentration below the lower limit of detection (LLOD) were assigned an MMP28 concentration of $50 \%$ of the LLOD for analytical purposes. These data were analyzed with non-parametric tests. In primary analysis, we tested for associations between AMspecific MMP28 gene expression (relative quantification) and VFDs. In secondary analysis, we tested for associations between AM-specific MMP28 gene expression or BALF MMP28 protein levels and P/F ratio, \% PMNs, and alveolar total protein levels.

Higher AM MMP28 gene expression at the time of ARDS onset was associated with worse VFDs (Fig. 1a, groups were dichotomized by the median VFDs). We next tested whether AM MMP28 gene expression on day 1 was associated with $\mathrm{P} / \mathrm{F}$ ratio to determine whether there was a link between AM MMP28 gene expression and a lung-specific endpoint. Higher AM MMP28 gene expression was associated with worse $\mathrm{P} / \mathrm{F}$ ratio (Fig. $1 \mathrm{~b}$ groups were divided into mildmoderate $(\mathrm{P} / \mathrm{F}>150)$ vs. moderate-severe $(\mathrm{P} / \mathrm{F}<150)$ based on a recent classification of ARDS severity [6]). In secondary analysis, we found that higher BALF MMP28 concentrations were associated with worse P/F ratio, but not VFDs (Fig. 1c, d). Increased BALF MMP28 concentrations were associated 
A.

AM MMP28 Gene Expression

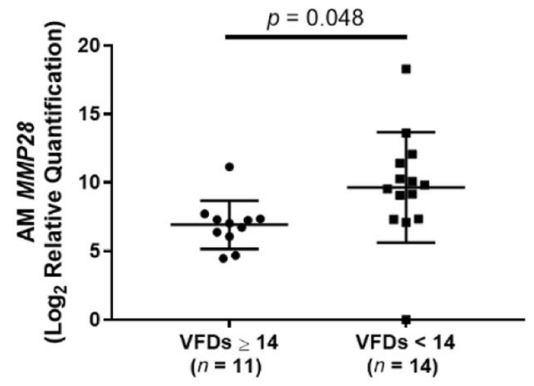

Ventilator-Free Days (VFDs)

C.

BALF MMP28 Concentration

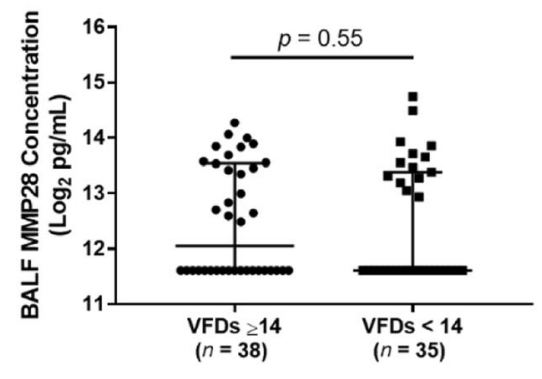

Ventilator-Free Days (VFDs)

E.

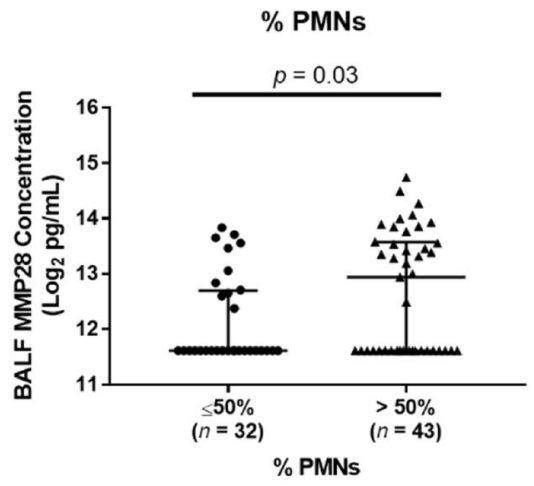

B.

AM MMP28 Gene Expression

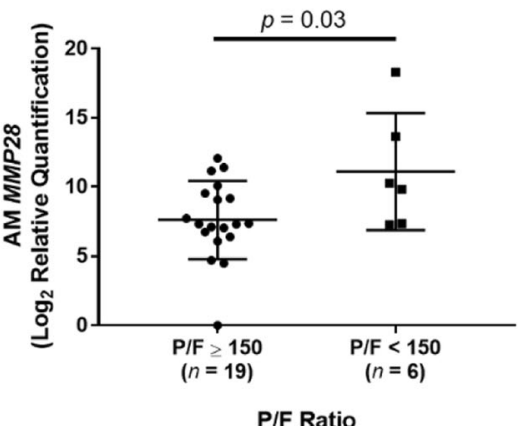

D.

BALF MMP28 Concentration

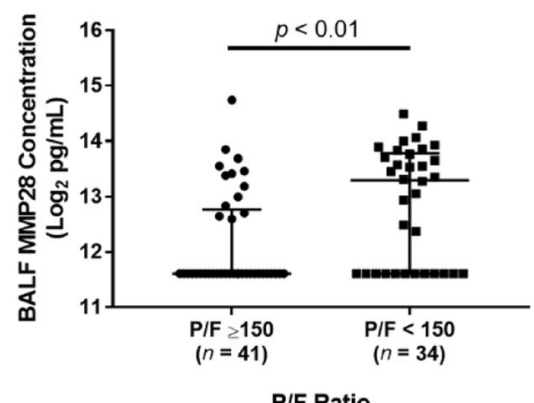

F.

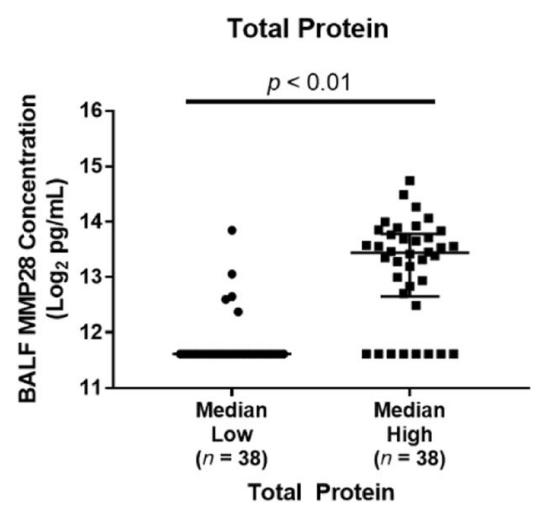

Fig. 1 Alveolar MMP28 is associated with clinical outcomes in subjects with acute respiratory distress syndrome (ARDS). a AM-specific relative gene expression of MMP28 was higher in subjects with worse ventilator-free days (VFDs) (VFDs < 14) vs. better VFDs (VFDs $\geq 14)(p=0.048$, unpaired $t$ test). Subjects were divided by the median VFDs $(V F D=14)$. Shown are the individual values, mean, and standard deviation. b AMspecific relative gene expression of MMP28 was higher in subjects with a $\mathrm{P} / \mathrm{F}$ ratio $<150 \mathrm{vs}$. $\mathrm{P} / \mathrm{F}$ ratio $\geq 150$ ( $p=0.03$, unpaired $t$ test). Shown are the individual values, mean, and standard deviation. C) BALF MMP28 concentrations were not different in subjects with worse VFDs (VFDs $<14$ ) vs. better VFDs (VFDs $\geq 14)(p=0.55$, Wilcoxon rank test). Shown are the individual values, median, and interquartile range. $\mathbf{d}$ BALF MMP28 concentrations were higher in subjects with a $\mathrm{P} / \mathrm{F}$ ratio $<150$ vs. $\mathrm{P} / \mathrm{F}$ ratio $\geq 150(p<0.01$, Wilcoxon rank test). Shown are the individual values, median, and interquartile range. e BALF MMP28 concentrations were higher in subjects with \% PMNs $>50 \%$ vs. subjects with $\%$ PMNs $\leq 50 \%$ ( $p=0.03$, Wilcoxon rank test). Shown are the individual values, median, and interquartile range. $\mathbf{f}$ BALF MMP28 concentrations were higher in subjects with higher alveolar total protein vs. subjects with lower alveolar total protein $(p<0.01$, Wilcoxon rank test). Subjects were divided by the median alveolar total protein concentration $(306.5 \mu \mathrm{g} / \mathrm{mL})$. Shown are the individual values, median, and interquartile range 
Table 1 Subject characteristics

\begin{tabular}{ll}
\hline Characteristic & $\begin{array}{l}\text { ARDS cohort } \\
(n=76)\end{array}$ \\
\hline Demographic & $50 \pm 16$ \\
Age (mean \pm SD) & $45 / 31$ \\
Sex (M/F) & \\
Comorbidities & $16(22 \%)$ \\
Diabetes & $5(7 \%)$ \\
Cirrhosis & $2(3 \%)$ \\
Chronic renal insufficiency & \\
ARDS risk factor ${ }^{*} n(\%)$ & $48(64 \%)$ \\
Sepsis & $31(41 \%)$ \\
Pneumonia & $27(37 \%)$ \\
Trauma & $8(11 \%)$ \\
Other & \\
Physiologic & $156,(121-205)$ \\
P/F Ratio (median, IQR) & $22 \pm 7$ \\
APACHE II (mean \pm SD) & \\
Outcome & $14,(0-21)$ \\
VFDs (median, IQR) & $11,20 \%$ \\
Mortality (28-day) $(n, \%)$ & \\
\hline ARDS risk facts a nom &
\end{tabular}

*ARDS risk factors are not mutually exclusive; APACHE Acute Physiology, Age, Chronic Health Evaluation, ARDS acute respiratory distress syndrome, IQR interquartile range, $P / F$ ratio $\mathrm{P}_{\mathrm{a}} \mathrm{O}_{2} / \mathrm{F}_{\mathrm{i}} \mathrm{O}_{2}$ ratio, $S D$ standard deviation, VFDs ventilator-free days-defined as the number of days a subject is alive and free from mechanical ventilation between day 1 and day 28 after enrollment. If a subject died before day 28 , they were considered to have VFDs $=0$

with increased \% PMNs and total protein concentrations (Fig. 1e, f).

Our study is the first in humans to demonstrate that increased AM MMP28 gene expression within the first $48 \mathrm{~h}$ after ARDS onset is associated with worse VFDs. Future studies that employ alveolar sampling are needed to validate the findings from this single-cohort association study.

\section{Abbreviations}

AM: Alveolar macrophage; ARDS: Acute respiratory distress syndrome BALF: Bronchoalveolar lavage fluid; ELISA: Enzyme-linked immunosorbent assay; MMP: Matrix metalloproteinases; $\mathrm{P} / \mathrm{F}$ ratio: $\mathrm{P}_{\mathrm{a}} \mathrm{O}_{2} / \mathrm{F}_{i} \mathrm{O}_{2}$ ratio; $\mathrm{RQ}$ : Relative quantification; VFD: Ventilator-free days

\section{Authors' contributions}

A.M.M. contributed to the conception of the work. E.D.M., M.M.W., C.M., and A.M.M. contributed to the design of the work. E.D.M., K.G., S.K., M.M.W., C.M., and A.M.M. contributed to the acquisition, analysis, and interpretation of the data for the work. E.D.M., C.M., M.M.W., and A.M.M drafted and revised the manuscript for important intellectual content. E.D.M., K.G., S.K., M.M.W., C.M., and A.M.M. significantly contributed to and approved the final version of the manuscript for publication. E.D.M., K.G., S.K., M.M.W., C.M., and A.M.M. agree to be accountable for all aspects of the work. All author(s) read and approved the final manuscript.

\section{Funding}

NIH NHLBI P50 HL073996 (Dr. Wurfel), NIH K23 HL144916 and Francis Family Foundation/Parker B. Francis Fellowship (Dr. Morrell), NIH K23 HL120896

(Dr. Mikacenic), NIH R01 HL116514 (Dr. Manicone).
Availability of data and materials

The datasets used and analyzed during the current study are available from the corresponding author on reasonable request.

Ethics approval and consent to participate

All studies were approved by the Human Subjects Division at the University of Washington.

\section{Consent for publication}

Not applicable

\section{Competing interests}

The authors declare that they have no competing interests.

Received: 25 February 2020 Accepted: 23 March 2020

Published online: 08 April 2020

References

1. Maldonado M, Buendía-Roldán I, Vicens-Zygmunt V, Planas L, Molina-Molina M, Selman M, et al. Identification of MMP28 as a biomarker for the differential diagnosis of idiopathic pulmonary fibrosis. PLoS One. 2018;13: e0203779.

2. Manicone AM, Birkland TP, Lin M, Betsuyaku T, van Rooijen N, Lohi J, et al. Epilysin (MMP-28) restrains early macrophage recruitment in Pseudomonas aeruginosa pneumonia. J Immunol. 2009;182:3866-76.

3. Gharib SA, Johnston LK, Huizar I, Birkland TP, Hanson J, Wang Y, et al. MMP28 promotes macrophage polarization toward M2 cells and augments pulmonary fibrosis. J Leukoc Biol. 2014;95:9-18.

4. Morrell ED, Bhatraju PK, Mikacenic CR, Radella F, Manicone AM, Stapleton $\mathrm{RD}$, et al. Alveolar macrophage transcriptional programs are associated with outcomes in acute respiratory distress syndrome. Am J Respir Crit Care Med. 2019;200:732-41.

5. Stapleton RD, Martin TR, Weiss NS, Crowley JJ, Gundel SJ, Nathens AB, et al. A phase II randomized placebo-controlled trial of omega-3 fatty acids for the treatment of acute lung injury. Crit Care Med. 2011:39:1655-62.

6. Maiolo G, Collino F, Vasques F, Rapetti F, Tonetti T, Romitti F, et al. Reclassifying acute respiratory distress syndrome. Am J Respir Crit Care Med. 2018;197:1586-95.

\section{Publisher's Note}

Springer Nature remains neutral with regard to jurisdictional claims in published maps and institutional affiliations.
Ready to submit your research? Choose BMC and benefit from:

- fast, convenient online submission

- thorough peer review by experienced researchers in your field

- rapid publication on acceptance

- support for research data, including large and complex data types

- gold Open Access which fosters wider collaboration and increased citations

- maximum visibility for your research: over $100 \mathrm{M}$ website views per year

At $\mathrm{BMC}$, research is always in progress.

Learn more biomedcentral.com/submissions 